\title{
Waste Reduction for Green Service Supply Chain-the Case Study of a Payment Service Provider in Iran
}

\author{
Ali Aghazadeh Ardebili ${ }^{1, *} \mathbb{C}$, Elio Padoano ${ }^{1} \mathbb{D}$ and Najmeh Rahmani ${ }^{2}$ \\ 1 Department of Engineering and Architecture, University of Trieste, 34127 Trieste, Italy; padoano@units.it \\ 2 Department of Research \& Planning, Statistics and planning office, SEP Co., Tehran, Iran; n.rahmani@sep.ir \\ * Correspondence: ali.aghazadehardebili@phd.units.it; Tel.: +39-327-197-5278
}

Received: 16 January 2020; Accepted: 25 February 2020; Published: 29 February 2020

check for updates

\begin{abstract}
Analyzing and designing how service is provided to the customer is crucial for sustainable supply chains in services. In this respect, there can be barriers to applying sustainable improvements due to regulations, practices and customer culture. This study is focused on finding the waste produced by the service of one of the biggest payment service provider (PSP) companies in Iran and how to meet the essential needs of the sustainable supply chain. It has been observed that using thermal papers as a biohazardous material causes environmental problems and even it is hazardous to mix them with normal paper waste in the recycling process. Moreover, preventive maintenance of the thermal printers itself causes a huge number of unnecessary shuttles between the customers and service suppliers, which represents a source of $\mathrm{CO}_{2}$ emission, traffic - especially in the capital—and high maintenance costs for the company. Three main alternatives to the thermal paper receipt were analyzed and ranked by means of a TOPSIS (Technique for Order of Preference by Similarity to Ideal Solution) model, which employed the sustainability pillars and the technical point of view as evaluation criteria. The priorities against the set of criteria were obtained by means of surveys, which targeted a sample of customers and a pool of experts. The results highlighted that customers' habits and legislation are the most important barriers to the transition to a more sustainable service.
\end{abstract}

Keywords: Sustainable supply chain; green service; payment service provider; thermal paper; waste reduction; multi criteria decision making; TOPSIS; sustainable consumption

\section{Introduction}

A service provider (SP) is an organization that performs a sequence of activities to satisfy a need for a specific group of customers or for the general public. Consultancies, financial services, and telecommunication services are typical examples of SPs. The service is delivered to the users by means of a chain of activities, which may involve several partners: planning and managing the supply chain is therefore a key aspect of this business A sustainable service supply chain (SSSC) is a combination of a group of companies utilizing their resources to meet the end user's demand in an efficient way and at the right time. In the last decade, the concept of sustainability has been introduced in SSSCs, but the body of knowledge on green service supply chains is not sufficiently structured yet. In addition, both from the users' and the managerial perspectives the advantages of programs aimed at introducing sustainability in this field are not completely clear. Therefore, the presentation and discussion of case studies on SSSC is particularly significant.

The present study is focused on the payment service and, more specifically, investigates the case study of one of the biggest payment service provider (PSP) companies in Iran. PSPs offer core services (e.g., the technical processing of payments) and some complementary services that concern the same activity 
(e.g., the payment transaction) and are valuable to their customers. In particular, every transaction is confirmed by the production of a receipt that is usually printed on thermal paper. Previous research shows that thermal paper, being biohazardous material, causes environmental problems, and it is even hazardous to mix it with normal paper waste in the recycling process. On the other hand, using these papers and thermal printers enforce the PSP companies to provide maintenance service for the POS (Point of Sale) machines throughout the country. In a recent report (February 2019 [1]), Ibena (Iranian economic and banking news channel) highlighted that thermal papers are one of the most relevant consumable costs for the banking network and payment service sector in Iran. Moreover, the preventive maintenance (PM) of the thermal printers itself causes a huge number of unnecessary trips that are mostly made by car or motorcycle.

It is worth remarking that payment services are widespread and a large part of their processes are based on digital technology. However, even if the payment transaction receipt can be digital, in many countries, the users still show a tendency to print it: the volumes of thermal paper used and the associated environmental costs are not negligible. For instance, a study by Yaaguby [2] points up that the thermal paper receipts used in Iran in six months could wrap around the earth nine times. Plans of waste reduction in this sector could therefore produce considerable environmental benefits. Nevertheless, the scientific literature on the subject is still rather limited. The present paper offers a contribution to the discussion on the transition of the payment service supply chain towards sustainability, highlighting some obstacles to an otherwise technically feasible digital transformation of the whole service.

The study investigates the case of a PSP that delivers its services through a mix of "soft" activities (e.g., the digital payment) and "hard" activities (e.g., the production of the paper receipt). One of the company's strategic goals is to remove the waste from the service supply chain, making it more sustainable and efficient. On this account, the identification of technically feasible alternatives to deliver the complementary service is a first step of the study, which aims to address the question: what are the alternative ways for the thermal paper receipt, which are feasible for the target company? The analysis and evaluation of the alternatives was then carried out, in order to answer a second question: which alternative is the most effective in enabling the transition towards sustainable service, ensuring a service that is reliable and acceptable for the users? The evaluation surely depends on the main actors of the payment service, namely the PSP and the users (sellers and customers), and on the regulations in force in the specific country, which may impose requirements and limitations to the technical solutions. Furthermore, the evaluation criteria should be related to the above mentioned company's goal and to the key dimensions of sustainability. In summary, in order to address the two questions, the methodology is based on a multi-criteria model in which the feasible alternatives are assessed against a set of criteria validated by the company managers and the priorities are obtained by means of empirical surveys administered to the payment service provider and users. The present study is an attempt to provide the company with a structured method for aiding the identification and selection of the most effective solutions, and, at the same time, to individuate the barriers to improving the sustainability of the payment service supply chain.

The next section presents the results of the review of the scientific literature that points out the research gap concerning sustainability in the payment service supply chain. Section 3 illustrates the general methodology employed to address the above mentioned questions and its application to the selected case study. The results of the application are presented in Section 4 and discussed in Section 5 . Some concluding remarks are included in Section 6.

\section{Literature Review}

The service supply chain links the service provider to other businesses or end users. The SP delivers value added services by means of a chain of activities that can be "hard" (such as the production or management of physical entities) or "soft" (such as the transmission of digital data). The nature of the service, the characteristics of the SP and their clients may influence the mix of hard and soft activities, 
and the features of the service supply chain. In particular, the transition to a green service depends both on the strategic objectives of the service and on the clients' behavior. Indeed, the consumers' behavior is a critical issue, which influences the cost and performance of the whole process in the service providing sector [3]. A recent study by Pagell and Shevchenko emphasizes several dimensions of sustainability in supply chains and highlights the importance of environmental and social issues: "Future SCM research will have to treat a supply chain's social and environmental performance as equally or more valid than economic performance" [4].

In order to individuate the studies related to sustainable services, a structured search on the Scopus database was carried out. The search was limited to peer-reviewed papers and the language was limited to English by click box selection in the advanced search toolbox of Scopus database.

The process of literature review included the following steps:

1. search for relevant literature on PSP (only one paper published in Scopus);

2. search for relevant literature on sustainability in the service sector, digital services and sustainability, MCDM in sustainability studies in the service sector;

3. evaluate the relevance of sources;

4. report the highlights in the literature review.

Scopus was selected since it is the largest abstract and citation database of peer-reviewed literature. The results are shown in Figure 1. The string of the search on the database is as follows:

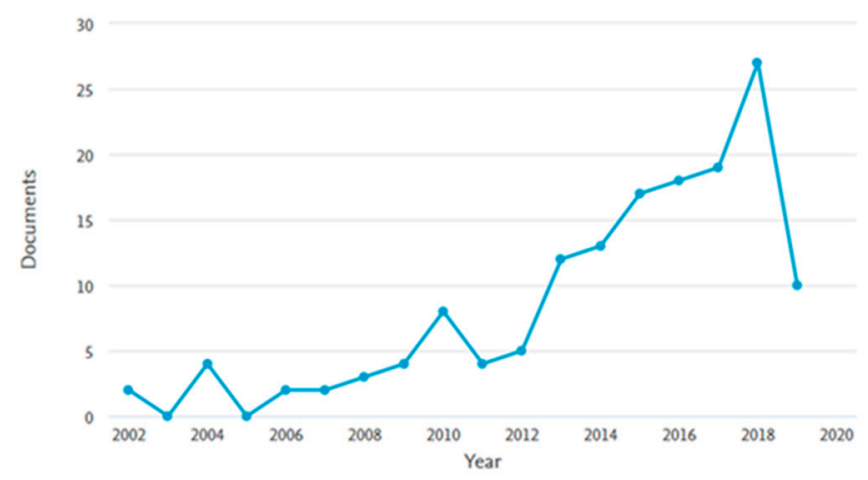

Figure 1. Recent published papers on the service supply chain (Database: Scopus).

TITLE-ABS-KEY (("service provider" OR "service providing") AND ("sustainable" OR "sustainability" OR "Circular Economy" OR “Green") AND ("supply chain")).

Notwithstanding some studies are focused on natural systems and the influence of sustainable supply chain (see e.g., [5]), the research on socio-ecological integrated systems has not been carried out in the service sector as much as in the production supply chain. In particular, most of the case studies are limited to the last five years. Papetti and colleagues suggested the web-based platform as a tool for eco-sustainable supply chain management [6] and Hussain and colleagues studied sustainability of the health care service supply chain [7]. Figure 1 illustrates the trend in the studies on the sustainability of service supply chains. The figure reveals that only 122 peer reviewed documents including 91 journal papers and 31 conference papers have been recently published which are significantly related to the topic "sustainable service supply chain". The line graph in Figure 1 shows a sharp increase in the quantity of the publications in the last seven years; furthermore, comparing our literature review to the one by Liu et al. [8], we also witness a significant increase from 2017 to 2019. Nevertheless, the Scopus database does not include any studies related with sustainability of payment services, while only one paper investigates the PSP supply chain, which is focused on the internet of things and the importance of the service supply chain to achieve a positive return on investment [9].

The main activity of a payment service provider (PSP) is selling and buying for the end users. This service was studied in detail by O'Mahony in 1997 [9]. Payment methods include e-commerce, 
mobile payment, online banking, credit cards, bank transfer and others. Usually, PSP is connected to multiple banks and uses a wide range of banking networks. The largest part of the core and ancillary services offered by PSPs are digital services. The service supply chain connects online service providers, retailers and wholesalers, and the end customers that use online payment service to pay. PSPs also offer complementary services like the production and delivery of documents such as the transactions receipts. Documents can be produced in digital (soft) or physical (hard) formats, which imply different flows of activity and materials. In many contexts, the electronic payment service is traditionally enabled by POS terminals whose management requires supplying material and other supporting services (e.g., maintenance). Other complementary services may require the management of hard activities and materials; thus, they could be subjected to close scrutiny in order to improve the service sustainability.

Since the studies that focused on PSP service are limited to one published paper, the authors decided to perform a second search on Scopus in which only two general keywords were used: "Sustainab*" and "Digital services". 71 indexed papers were found. Several of them report studies on the digitalization of services that have been usually delivered by means of hard activities. Supply chain and logistics are the most popular subject areas, where solutions of smart mobility and transportation have been evaluated considering $\mathrm{CO}_{2}$ emission as the key environmental aspect [10-15]. In a case study of YouTube as a digital service provider in 2019, Preist et al. investigated how Sustainable Interaction Design of digital services can contribute to the corporate strategies for greenhouse gas (GHG) reduction [16]. Koukopoulos et al. in 2019 presented a prototype digital system that supports the goal of sustainability for a modern public library [17]. However, the main objective of this study was attracting a wider audience of library visitors and provide new sources of revenue. Digital product-service-systems constitute another investigated subject area [18]. In 2017, Agbozo studied the development of a digital government framework, and he considered the social aspects of sustainability and eService adoption, cybersecurity challenges, etc. [19].

In the last decade an interest in intangible offerings and service innovation has emerged, replacing the focus on tangible products and "hard" activities. In this respect, the popularity of product-service innovation (PSI) is increasing because of the inherent interrelation between firm performance and PSI [20]. In production firms, the customer and logistics IT processes are considered the necessary basic elements of service innovation [21]. A recent stream of research conducted by a group of European researchers has focused on product-service innovation (PSI) and green servitization [20-24]. They studied different companies that implement digital solutions to support business operation. For example, they highlighted the role of "firms willing to offer green services should consider offering digital services first" [22]. Sectoral studies reveal that remanufacturing and recycling in the computer and electronics industry increases flexibility and sustainability of the supply chain [23], and implementing digital and green servitization causes significant increase of firms productivity in the automotive industry [22]. Also, in food companies of the retailing sector, companies try to add new value to products by promoting digital servitization to gain competitive advantages [24].

Many of the analyzed papers explore means of digitalizing the activities of production, transfer and storing of information connected with the core services, which, as e.g., in logistics, often require hard activities. In the payment service, while the core service is mainly delivered through soft activities, the complementary service of documenting the transaction is traditionally based on hard activities. The receipt is printed on thermal papers using POS terminals. Thermal receipts are widely used in payment services. Most of the POS terminals, shopping receipt in selling points and shops and automated teller machines (ATM), which print a paper receipt, use this sort of paper. The paper is coated with different chemicals to make it printable and the reactant acid in coating material is mostly Bisphenol A (BPA). Several epidemiology studies disclose BPA exposures and threats of adverse health outcomes [25-29]. Because BPA is hazardous, mixing thermal paper receipts with other material to recycle them should be avoided. Indeed, BPA can contaminate other recycled paper products including paper bags or toilet paper. 
On account of the diffusion of payment services, the volumes of thermal paper used and the environmental costs that it can cause, the scarcity of studies on this topic testifies a notable gap in the research on sustainable services. It is worth remarking that this complementary service is indeed a value-added service for the client and it is required by the regulations of many countries. Alternatives to the printed transaction receipts should then be identified and evaluated in order to reduce the waste and impacts produced by the service. It is therefore necessary to individuate attributes or criteria of sustainability that can be valid for the service sector and employ a method that can support the evaluation in presence of several criteria.

In sustainability studies, the criteria or indicators used by researchers in quantitative analysis and multi-criteria decision making (MCDM) methods are different and depend on the subject area. For instance, in agricultural studies, Balezentis et al. used four criteria (total output, total water footprint, Shannon equitability index and downside coefficient of yield variation) [30]; while in aquaculture Martinez-Cordero and Leung tried to find the best decision regarding the employment, foreign exchange earnings, economic rent maximization, and total pollution minimization, subject to land availability and local market demand constraints [31]. The emergence of new concepts such as "servitization" and product-service systems (PSS) highlighted the need to consider socio-ecological aspects [32]. In this case, the interrelation between the services to enhance the production is the main objective. In 2019, Zhao et al. used customer centricity, service efficiency enhancement, reduced credit risk, and the development of scenario finance as criteria in a study to improve "Financial Service Innovation Strategies" for improving China's Banking Industry [33]; nevertheless, the main goal of the authors was creating competitive advantage. Also, Raut et al. focused on banking service and introduced 32 criteria for sustainability in the banking industry [34]. However, the published studies that follows quantitative multi-criteria/attribute analysis in the context of sustainable services are rather limited.

In the sector of pure services, i.e. where services are not related to manufacturing, the studies that used MCDM approaches are very limited and they mainly include the healthcare, urban mobility and transport, and hospitality services. For example, a paper by Liu et al. in 2019 was focused on health care service and the authors used integrated decision making trial and evaluation laboratory (DEMATEL)-based analytic network process (DANP) and a modified VIKOR (VIseKriterijumska Optimizacija I Kompromisno Resenje) method to form a DDANPMV (DEMATEL + DANP + Modified VIKOR) model to examine consumers' adoption of mobile health care to promote the sustainable development of medical resources [35]. Moslem et al. analyzed stakeholder consensus for a sustainable transport development decision by the Analytic Hierarchy Process (AHP) [36] and Ozturkoglu et al. studied the dimensions for "sustainability-oriented hospitality service innovation (SOHSI)" [37]. These studies were all published in 2019, showing that research on the application of decision support tools like MCDM for the evaluation of sustainable solutions in the service sector is still lacking.

\section{Materials and Methods}

\subsection{General Methodology}

The review of the literature allowed to highlight that the payment service includes, alongside core services, a complementary service that is an important source of environmental impact, which must be mitigated for a transition to green services.

Hence, the questions that this study aims to address are:

- What are the alternatives to the thermal paper receipt, which are feasible for the specific company?

- Which alternative is the most effective in fulfilling the following goals: enable the transition towards sustainable service and ensure a service that is reliable and acceptable for the users?

A methodological framework is here proposed which aims at the identification and assessment of alternative ways to provide the transaction receipt in a specific setting. The study is mainly empirical 
and based on the direct observation of a selected case study, to which the framework is applied. The study follows these steps respectively: identification of the case-study, data collection to identify the alternatives to thermal paper (first data collection phase), identification of a MCDM method to evaluate the alternatives, data collection to quantify the evaluation criteria (second data collection phase), production of MCDM results.

Data were collected by means of five groups of interviews, which were conducted in two phases. In the first phase, two unstructured interviews (in-depth interview: see Legard et al. [38]) and one semi-structured interview were carried out to collect data about the mission of the company, sequence of activities, organizational information, end users, and the wastes produced in the service process and alternative methods. The company investigated in this paper (Saman Electronic Payment - SEP) is a typical example of PSP. The list of activities is published in their website and available to the public, and customers are widespread in the whole country. The semi-structured interview was focused specifically on SEP. A list of pre-defined questions was used, but, during the interviews, additional questions might have been asked to clarify specific points. In this phase, the interviewees were software engineers, who had the expertise required to explore the possibilities of software development to eliminate the paper receipts in SEP, a POS terminal maintenance technician of SEP and experts from the company. The main goal of this phase was to obtain the information useful to identify the alternatives to thermal paper.

The second phase of data collection included two stages, which were aimed to provide information to perform a MCDM analysis for prioritizing the alternatives to using the paper receipt. The first stage was the data collection from the end users and the second stage was the interview with the hardware and software development experts of SEP. Six criteria belonging to two groups were employed in the ranking model. The first group includes three pillars of sustainability, the second three criteria are associated with the company. The pillars include social aspects, environmental effects and economic issues related to sustainability. The second group of three criteria regards the company's capacity to change to a sustainable service by providing a new reporting service method, which requires software and hardware development. An important criterion of this second group is the cost of utilizing an alternative method. Figure 2 illustrate the general steps of the research conduction in a flowchart.

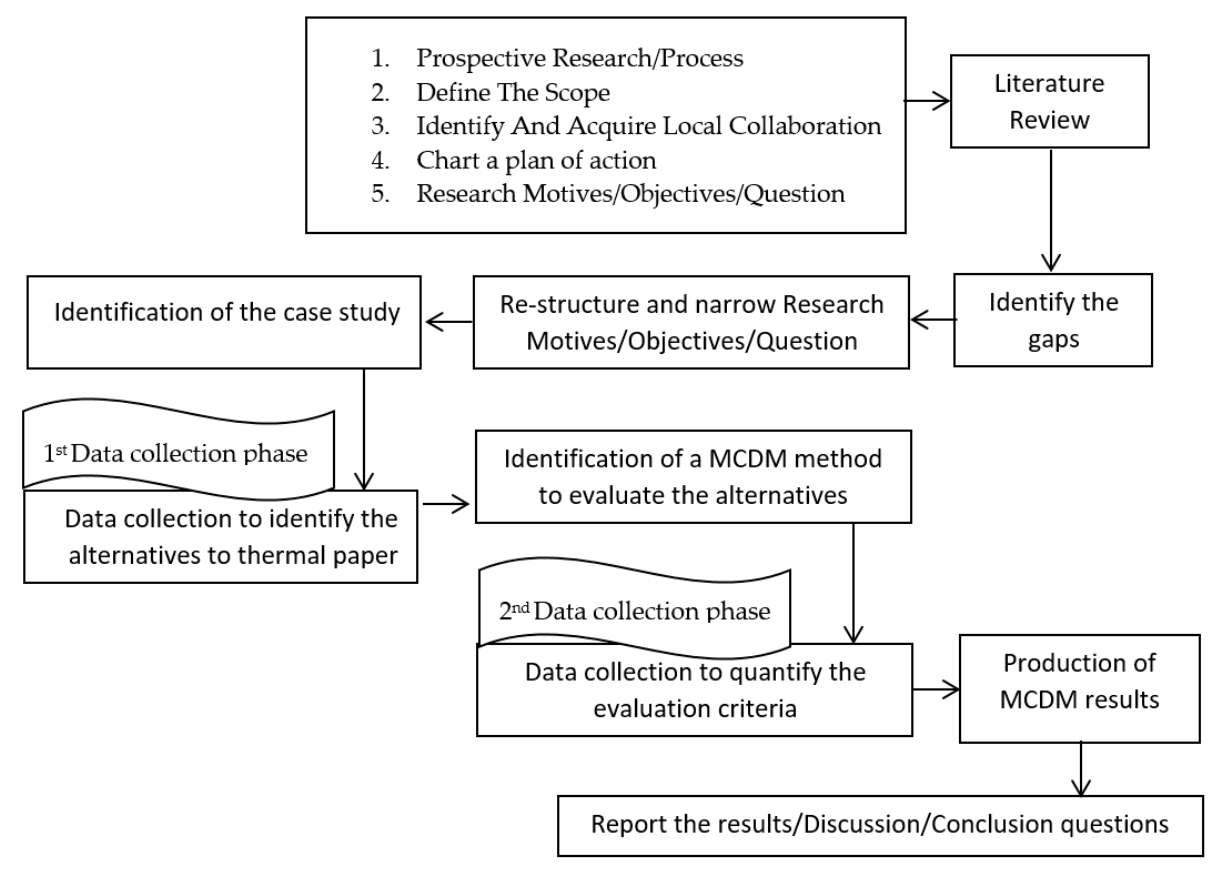

Figure 2. General methodology and research process flowchart. 


\subsection{Case Study}

There are more than 900 PSP active in the world. SEP is an active PSP in Iran. In this kind of companies, profit is based on a percentage of the transaction or fixed price for each transaction. There are two main categories of costs for PSPs. The first category is related to the management of the system, including hardware, human resources and other overheads of the company. The second category includes variable costs of consumables such as thermal paper, which is used as receipt, and the maintenance service for POS machines. This second category can be reduced by means of proper planning. For instance, proactive maintenance by regular inspections could decrease the maintenance cost of POS terminals in retail stores $[39,40]$.

SEP was selected as a case study because of three reasons. First, the managers are open to sharing their knowledge and experiences with the research team and the personnel have sufficient scientific background to clearly understand the goals and expected results of the investigation. Second, the company has strict monitoring and reporting instructions, which are followed by all departments, including the maintenance units. Particularly the database is classified and archived effectively, which makes the information extraction more reliable. Third, this company has a high rank in the world, and it supplies only services.

SEP is ranked 23 in the world and second in Iran according to the Nilson report [41], which introduced the world's top 150 Acquirers in 2017; SEP recorded 2.695 million transactions in 2017. To provide such a wide service, this company has about 800,000 POS terminals and each maintenance technician is responsible for the maintenance and service of about 900 POS terminals. As a result, each technician checks the machines in 900 different places (but in the same region) at least once a month. These trips generate high levels of $\mathrm{CO}_{2}$ emission, traffic-especially in the capital-and high costs of maintenance for the company. The use of thermal paper is the only reason for such waste; therefore, eliminating it might not only increase the sustainability of the business but also decrease the costs and improve the reliability of the service.

The company operates in a context characterized by specific regulatory requirements. An obligatory instruction introduced by Shaparak, the branch of the central bank of the Islamic Republic of Iran, which is the responsible institution for the monitoring and control of electronic payment services in Iran - establishes to use a printed receipt in order to monitor the electronic transactions (SHP_STD_EFTPOSRECEIPT) [42]. This fact causes a high amount of expenditures, which include consumables, thermal printers and the maintenance of the POS terminals. PSPs have shortened the receipts by using smaller fonts and eliminating unnecessary information in order to reduce paper consumption and decrease the depreciation of the POS terminals.

\subsection{Application of the Methodology to the Case Study}

\subsubsection{Data Collection Phase}

The first phase of data collection allowed to obtain information about the technical and organizational aspects of the service provided by SEP and, eventually, to individuate the alternatives to using thermal paper receipts (see Section 4.1). As previously remarked, this phase was based on semi-structured interviews.

The data collected in the second phase were used to quantify the social criteria. Data were collected by means of a structured interview supported by a questionnaire that was distributed in a micro zone to collect data from the end users of the service. Two other structured interviews were conducted by distributing the same questionnaire in other regions in Tehran and in Mashhad to highlight differences or similarities between the micro zones, i.e. the city of Tehran and other parts of the country. The questionnaire was distributed randomly and included questions about the age, job, gender, and education to control the diversity of the sample. The questions were created with straightforward, unbiased Persian language. The questionnaire included open-ended 
questions, multiple-choice questions and scaling questions; the survey was performed as an in-house questionnaire and a researcher visited the micro zone to distribute it.

Because of the availability of data, a region northeast of Tehran was selected and Raste Bazare Shomale Sharg, Haft Hoz, Sharghi was selected as a micro-zone. To find the distances and the traffic situation in the selected zone for the trips of the maintenance technicians between the POS terminals locations, Google Map was used. To focus on the active service points, the maintenance technicians were traced by the company; in this study, the service points only include the latitude and longitude of the locations that the maintenance technicians visit for the regular monthly preventive maintenance program, not all of the addresses of the owners of POS machine.

Previous questionnaires on payment service, which were already validated by experts and which are available in surveymonkey.com, survey.askform.cn, and marketest.co.uk, were used as standard templates, so that the layout and style validity is guaranteed (Uniform Resource Locators - URL-are provided as supplementary material). The sample size was calculated on the basis of the average quantity of the end users in the micro zone who performed transactions in 4 consecutive months.

The adopted parameters are:

- $\quad 95 \%$ confidence level;

- the population is 2000 (the average of transactions in 4 months in the selected zone);

- response distribution, 50\% (considering the standard normal distribution without skewness, according to similar published studies conducted in the same service sector);

- $\quad$ sample size, 200;

$\operatorname{MOE}\left(\right.$ with finite population correction) $=z^{*} \sqrt{ }[\mathrm{p} *(1-\mathrm{p})] / \sqrt{ }[(\mathrm{N}-1) * \mathrm{n} /(\mathrm{N}-\mathrm{n})]$

where MOE is the margin of error (Equation 1): $\mathrm{z}$ is the $\mathrm{z}$-score associated with a level of confidence, $\mathrm{p}$ is the sample proportion, expressed as a decimal, $\mathrm{n}$ is the sample size, $\mathrm{N}$ is the population size. In this case, $\mathrm{MOE}= \pm 6.576 \%$; the value is acceptable since falls in the range between four and eight.

Connelly [43], Hill [44], and Isaac and Michael [45] suggest 10-30 participants for a pilot survey. Treece and Treece [46] suggest that in a pilot study the sample should be $10 \%$ of the sample. On such grounds, in this study, 2 pilot survey were conducted with 20 participants. The reliability and content validity were then evaluated by means of the pilot interviews. Moreover, clarity of wording was measured during the interview and all of the interviewees with different academic backgrounds and ages understood the queries easily without asking further clarifications. The Python language and three packages including NumPy, Pandas, and Matplotlib were used for data analysis of the results of the pilot survey. The code string of this section in Python is shown in Appendix A. Moreover, Figure A1 illustrates the comparison of the two pilot survey results in one of the questions, which was created by means of the above-mentioned code. Each pilot survey had 20 participants.

\subsubsection{Multi-Criteria Decision Making method}

TOPSIS (Technique for Order of Preference by Similarity to Ideal Solution) was selected to rank the alternatives. This method considers $\mathrm{m}$ alternatives (options) and $\mathrm{n}$ criteria and the outcome of each option with respect to each criterion to find the alternative that is the closest to the ideal solution and farthest from negative ideal solution. TOPSIS is a multi-criteria decision-making (MCDM) method and in this study, it is used aim to order the preferences based on similarity to ideal solution. Among the MCDM methods, TOPSIS is appreciated by many company managers as the two abstract ideal and negative ideal solutions are clear references for the positioning of the actual alternatives [47]: the ideals testify the best and worst, even if unattainable, solutions which are consistent with the decision makers' preferences [48]. In addition, the method simplifies the use summary measures (e.g., the average) obtained from judgements by many respondents. In this study, the resources and time to perform the survey and process the collected data were limited, and therefore it was decided to use the standard version of TOPSIS, which is based on crisp numbers. The classical TOPSIS analysis is popular between researchers in decision-making developed through the following steps [49,50]: 
Step 1:

Construct $m^{*} n$ matrix which have $X=\left(x_{i j}\right)$ elements and $x_{i j}$ is the performance of option $i$ with respect to criterion $\mathrm{j}$

Step 2:

Normalize the decision matrix with following equation:

$r_{i j}=x_{i j} / \sqrt{ }\left(\sum_{i} x^{2}{ }_{i j}\right)$ for $i=1, \ldots, m ; j=1, \ldots, n$

Step 3:

Construct the weighted matrix by assuming the weights of the criteria $w_{j}$ for $j=1, \ldots, n$ and multiply each column of the normalized decision matrix by its associated weight.

$\mathrm{v}_{\mathrm{ij}}=\mathrm{w}_{\mathrm{j}}{ }^{*} \mathrm{r}_{\mathrm{ij}}$

Step 4:

Determine the positive ideal and negative ideal solutions by following equations (where J is the sub-set of the criteria for which the maximum is best and $\mathrm{J}$ ' is the sub-set of the criteria for which the minimum is best):

$$
\begin{aligned}
& A+=\left\{v_{1}+, \ldots, v_{n}+\right\}, \text { where } v_{j}+=\left\{\max \left(v_{i j}\right) \text { if } j \subset J ; \min \left(v_{i j}\right) \text { if } j \subset J^{\prime}\right\} \\
& A-=\left\{v_{1^{-}}, \ldots, v_{n^{-}}\right\}, \text {where } v_{j^{-}}=\left\{\min \left(v_{i j}\right) \text { if } j \subset J ; \max \left(v_{i j}\right) \text { if } j \subset J^{\prime}\right\}
\end{aligned}
$$

Step 5:

Determine the Positive separation measures and Negative separation measures for each alternative by following equations:

$$
\begin{aligned}
& \mathrm{Si}+=\left[\sum_{\mathrm{j}}\left(\mathrm{v}_{\mathrm{j}}+-\mathrm{v}_{\mathrm{ij}}\right)^{2}\right]^{\frac{1}{2}} \quad \mathrm{i}=1, \ldots, \mathrm{m} \\
& \text { Si- }=\left[\sum_{\mathrm{j}}\left(\mathrm{v}_{\mathrm{j}^{-}}-\mathrm{v}_{\mathrm{ij}}\right)^{2}\right]^{\frac{1}{2}} \\
& \text { Step 6: }
\end{aligned}
$$

Calculate the relative closeness to the ideal solution $\mathrm{Ci}^{*}$ and choose the Alternative with $\mathrm{C}_{\mathrm{i}}{ }^{*}$ closest to 1:

$\mathrm{Ci}^{*}=\mathrm{S}_{\mathrm{i}}-/\left(\mathrm{S}_{\mathrm{i}}++\mathrm{S}_{\mathrm{i}^{-}}\right), 0<\mathrm{C}_{\mathrm{i}}^{*}<1$

The results of the ranking the alternatives are illustrated in Section 4 , and a discussion and conclusion provided which is reported respectively in Sections 5 and 6.

\section{Results}

\subsection{First Data Collection Phase}

\subsubsection{Thermal Paper}

SEP often purchases thermal papers for its POS terminals from the Soltanrol company. Hansol Paper and Indonesian producers presently have the highest share of thermal paper market in Iran. The characteristics of these products are the same: all of the thermal paper used by SEP contains BPA. The thermal papers are available in standard width and five colors. The average length of the receipt in Iran is $10 \mathrm{~cm}$, but it can depend on the province. For example, in Fars province, the length of the receipt is $12 \mathrm{~cm}$ but in Kermanshah Province, the length of the receipt reaches $29 \mathrm{~cm}$. Figure 3 illustrates different sizes of receipt which are offered by the same company. In all the formats, it is possible to include all the necessary information and thus decrease the length of the paper.

The total amount of thermal paper usage by SEP is 33,180,678 rolls (each roll is 18 meter long) during the first three months of the year. Table 1 reports the paper consumption in the selected region and micro-zone in three successive months. The paper consumption by retail sellers depends on the number of transactions. In addition, the retailer can take a report printed by the POS terminal in the shop. This report includes all of the transactions done by the same POS terminal; therefore, the length of this type of report could be even two-meter long. It is possible to retrieve a brief report or check the transactions online in the webpage of many PSPs; however, some sellers prefer to print it at the terminal. 


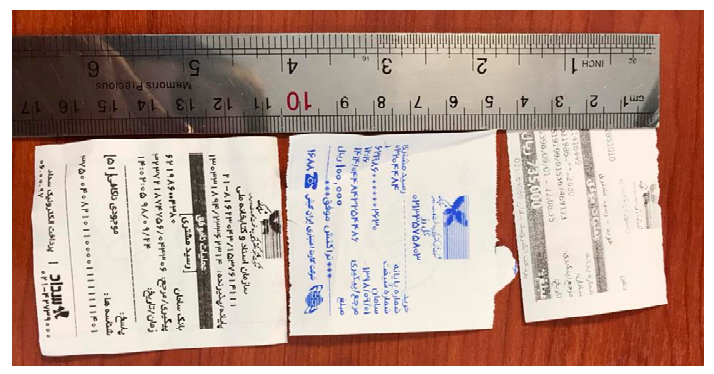

Figure 3. Thermal receipt samples of SEP in Iran with different sizes (Photo taken by the Authors).

Table 1. Transactions and paper consumption in three successive months.

\begin{tabular}{cccccc}
\hline Period & $\begin{array}{c}\text { Region } \\
\text { Transactions }\end{array}$ & $\begin{array}{c}\text { Transactions in } \\
\text { the Micro-Zone }\end{array}$ & $\begin{array}{c}\text { Consumption } \\
\text { in the Region } \\
(\mathbf{1 8 - m} \text { rolls) }\end{array}$ & $\begin{array}{c}\text { Consumption in } \\
\text { the Micro-Zone } \\
\text { (18-m rolls) }\end{array}$ & $\begin{array}{c}\text { \% of All } \\
\text { Companies' } \\
\text { Consumption }\end{array}$ \\
\hline $97.01^{1}$ & $1,044,666$ & 2393 & 601,000 & 1377 & $0.23 \%$ \\
$97.02^{1}$ & $1,265,885$ & 218 & 725,000 & 125 & $0.02 \%$ \\
$97.03^{1}$ & $1,288,454$ & 1128 & 851,400 & 745 & $0.09 \%$ \\
\hline
\end{tabular}

${ }^{1}$ The solar calendar is customary in Iran. In this study, the data belong to the first 3 months of the solar year 1397 regarding to Iranian calendar are used. In AD Calendar 01.0.1.1397 is 2018-03-21.

\subsubsection{Maintenance}

POS terminals are used to record and process the information related to sales at the retail stores; therefore, they are the end points of the service supply chain. POS terminals, which SEP or any other PSP company provide for selling points, shops, and banks, need maintenance. SEP uses a range of different POS terminals with different technical characteristics. SEP uses both traditional and high-tech POS terminals.

The interviewed SEP experts remarked that malfunction of POS terminals during business hours causes great dissatisfaction among customers. Therefore, the PSPs provide maintenance services through regular inspection to minimize failures. The maintenance procedure includes two main approaches: predictive maintenance (PM) and emergency maintenance (EM). An on-site technician carries out PM through monthly inspections. This includes functionality control, software tests, and hardware control beside component replacement when necessary. In some cases, it is necessary to check the functionality after software updates. The technician also supplies new thermal paper rolls to the customers on request.

Each technician is responsible for controlling about 900 POS terminals. After an inspection, the technician should perform a special transaction to record the service that he has provided to the customer. The most important point is that the POS terminals are distributed in different locations. For instance, there are 32 POS terminals in Raste Bazare Shomale Sharg Tehran, Haft Hoz, Sharghi region. The technicians mostly use a motorbike to reach the area and walk between the selling points if they are close to each other. As it is shown in Figure 4, in the example area, the longest distance is 4.2 kilometers.

Customers require emergency maintenance by telephone call. When emergency service is recorded, the closest branch sends one of the technicians to solve the problem. It is worth noting that the technicians are based in the capitals of the provinces and in case of an emergency call from the other cities of the province the closest branch sends a technician there. This implies transportation and cost to the maintenance department. In addition, the technician will not be available to carry out the assigned daily inspections; therefore, a new schedule should be identified for the technician in case EM happens. The most common problems include updating the software, changing the battery, replacing an exhausted paper roll, solving a printer paper jam and problems with the thermal printer when the print is not clear or quite absent. 


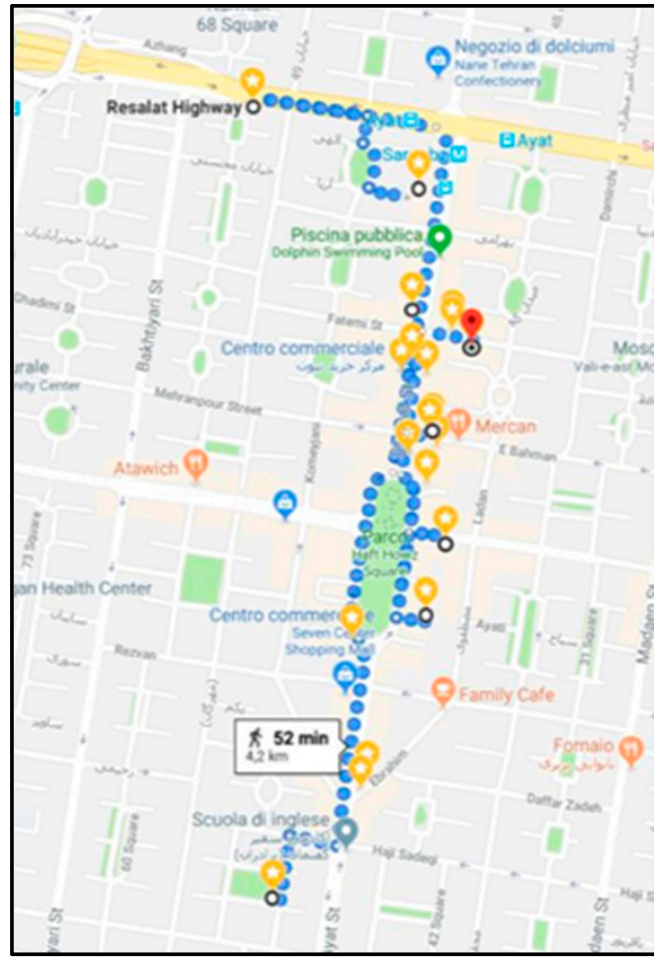

(a)

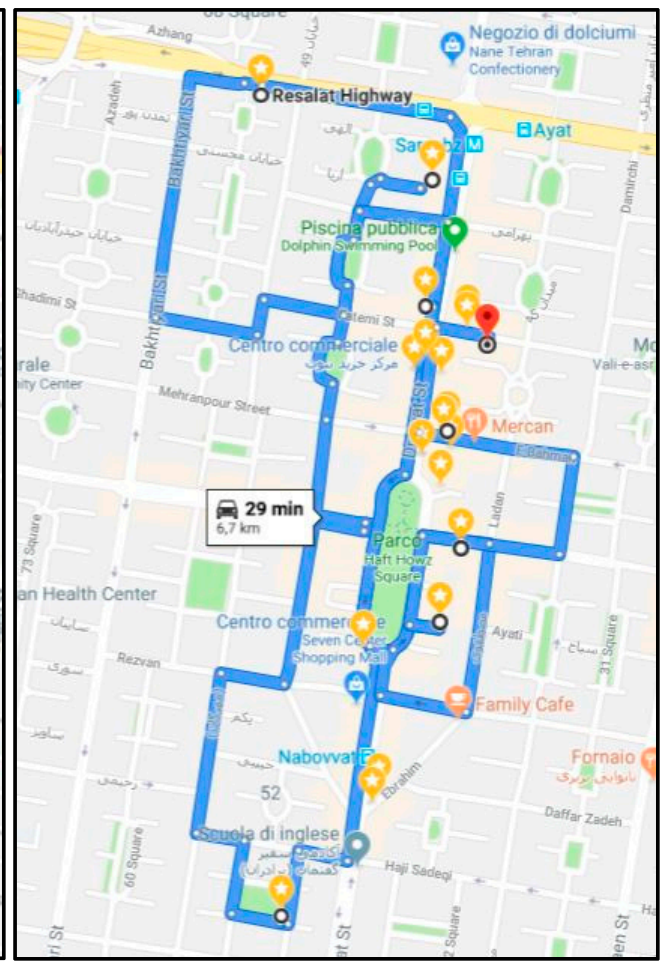

(b)

Figure 4. The distribution of the selling points in Raste Bazare Shomale Sharg Tehran-Haft Hoz-Sharghi. (a) walking rout between the selling points. (b) the driving route between the points.

\subsubsection{The Identified Alternatives}

The interviewed experts of the company suggested three alternative ways to allow a transition to green service. All the alternatives are based on the concept of electronic receipt (eReceipt) as a means to reduce the usage of thermal paper. Figure 5 shows the three alternative ways to deliver an eReceipt and their technical solutions.

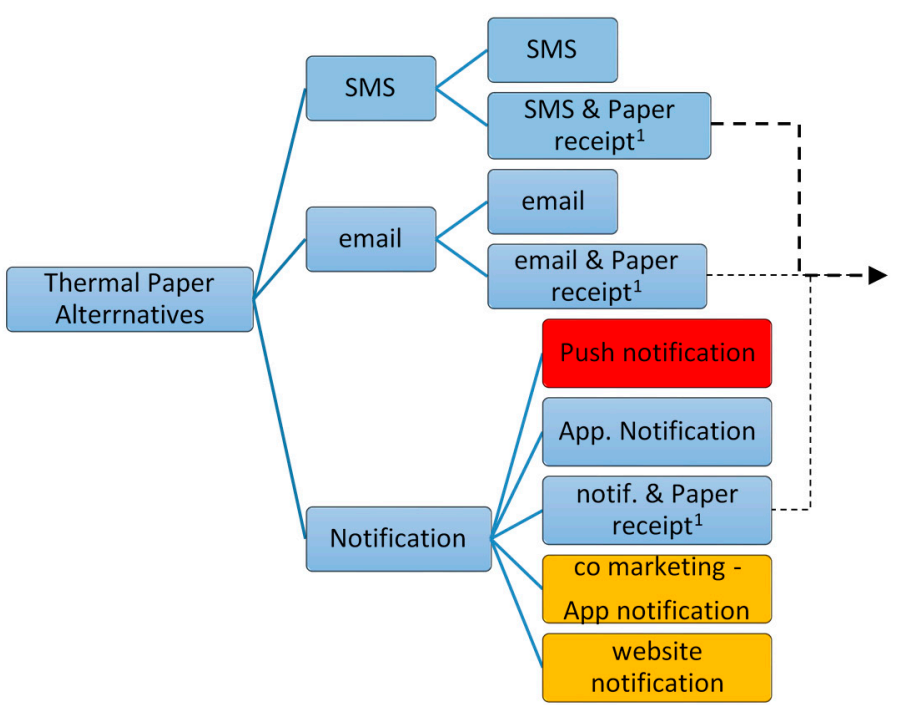

\begin{abstract}
${ }^{1} 18 \%$ of the surveyed end-users had the experience of using paper receipt as an official document for transaction tracking in case of problem. Therefore, when the transaction is successful the system will send an SMS, email, or notification otherwise the system will produce a print of unsuccessful transaction.
\end{abstract}

Figure 5. Thermal receipt Alternatives in Iran. 
The interview with an android POS developer of the company revealed that sending a push notification needs many changes in the existing reporting system and the software of the company. On the other hand, the process of sending push notification needs a cooperation with Telecommunication Company of Iran (TCI). TCI is a governmental operator in Iran offering telecommunication services in the whole country. This external company must be a partner in the process of sending SMS, but sending a push notification is problematic for the existing infrastructure of TCI. By all accounts, sending push notification is very complicated from the technical point of view and it is presently a very expensive service. Therefore, this option was eliminated from the possible alternatives.

Co-marketing means that SEP sends the eReceipt as a notification but not through its own application; therefore, the eReceipt will be sent through the application of other partner companies. The interviewed marketing expert of the company remarked that while such event is technically possible, at the moment and in the near future the company does not have any partner of such kind: therefore, this option was eliminated from the possible alternatives. Website notification is not applicable because the end users are not directly connected with the service provider. Co-marketing of the website notification is also not applicable because of the same reason highlighted for the application of co-marketing.

Near field communication (NFC) technology is another option, which could be fruitful to limit the paper receipts. Apple Pay, Samsung Pay, Android Pay, and others are using the same technology. However, it is possible to use NFC only if the terminal is also NFC-enabled and, as the Android POS developer expert said, "POS terminals of retail shops in Iran do not presently offer NFC for payment cards or smartphones".

\subsection{Second Data Collection Phase}

The final database includes 600 respondents. The age of the respondents follows a normal distribution (Figure 6). Moreover, $43 \%$ of the respondents are female and $57 \%$ are male. They are classified in more than 60 job categories and the educational taxonomy of the respondents includes primary school, high school, high school diploma, bachelor's and master's degrees and Ph.D. This variety confirms the diversity of the respondents. All 600 interviewees from different cities and differing by age, job, and education level use a PSP company's service in different forms.

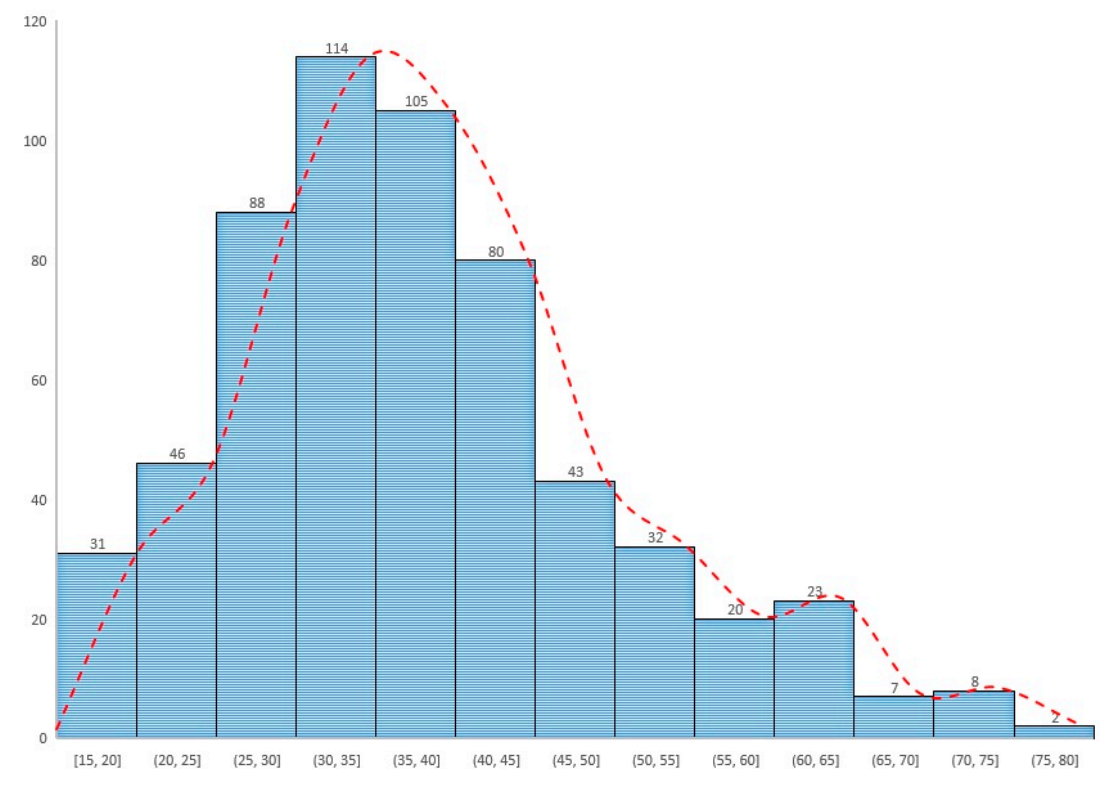

Figure 6. Age distribution of the respondents.

One of the questions was aimed to assess the level of environmental concern of the end users of the payment service were aim to assess of the final users of the online payment service (Figure 7) Another question investigated the habit of "Taking the paper receipt after the electronic payment" 
because the POS terminal prints it, only if the customer explicitly selects this option (Figure 8). As already mentioned, a micro-zone inside Tehran was selected for 200 random interviews, while the remaining interviews were done in other zones of Tehran and in another city. Figure 9 shows the interviewees' level of preference of using the printed receipt in the different places where the interview was conducted.

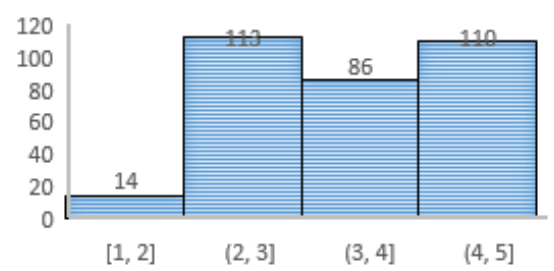

Figure 7. Concern for the environmental issues (y-axis: number of respondents, $x$-axis: the score in the 5-point Likert scale, 1 not concerned - 5 especially concerned).

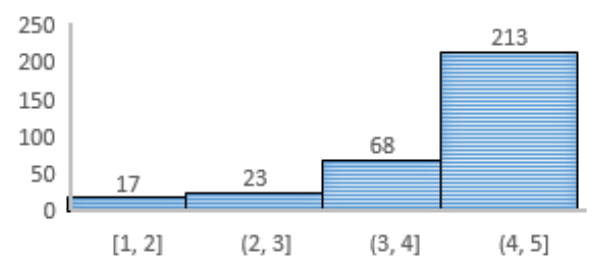

Figure 8. Taking paper receipt after electronic payment (y-axis: number of respondents, $x$-axis: the score in the 5-point Likert scale, 1 usually don't-5 usually do).

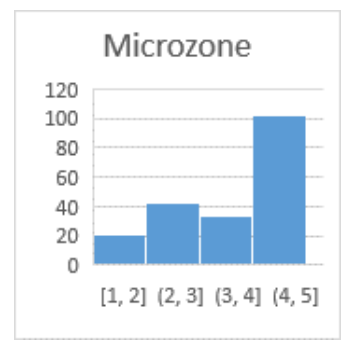

(A)

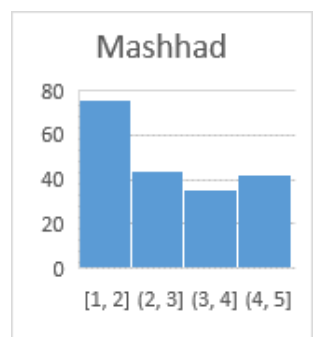

(B)

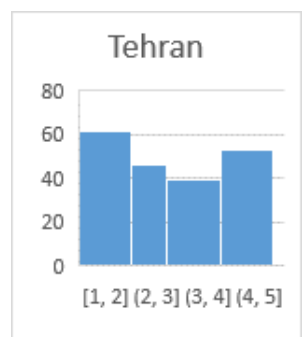

(C)

Figure 9. Comparing the end user preferences of using the printed receipt in Micro-zone (A), Tehran (B), and Mashhad (C).

\subsection{Ranking the Alternatives by TOPSIS}

This section presents the results of the application of the TOPSIS method to rank the alternatives to the printed receipts. The six alternatives (shown in blue in Figure 5) were assessed against six criteria. The criteria include three attributes related to the company and the feasibility of the alternative to using thermal paper, and three sustainability pillars (social, economic and environmental aspects). In the first phase of data collection, the experts of the research and development department of the company suggested to combine the environmental with the economic attribute of sustainability. The criteria were weighted after the interviews with SEP experts.

SMS, email and application can be used but regulation in force establishes that a hard copy be given to the customer in case of unsuccessful transaction. According to the collected data, the percentage of unsuccessful transactions in seven successive months is roughly $10 \%$. Therefore, the alternatives that require a print in the case of unsuccessful transactions (e.g., SMS and print) are scored $10 \%$ less than the corresponding pure electronic receipt. The successful transactions are illustrated in Figure 10. The hardware, software, and cost scoring were extracted from the interviews with the experts of the company. As the main goal of the study is to find the most sustainable alternative to thermal paper usage, the company experts agreed to give the sustainability pillars a weight of $25 \%$. Setting up new alternative hardware and software depend on some infrastructures and third parties 
that are external companies. On the other hand, the cost of introducing the new reporting system to limit the use of thermal paper receipt was weighted $10 \%$ because, according to the experts, it is less important than the technical possibility of setting up the new system; this testifies the current commitment of the company's senior management to sustainable development, environmental issues, and end user safety.

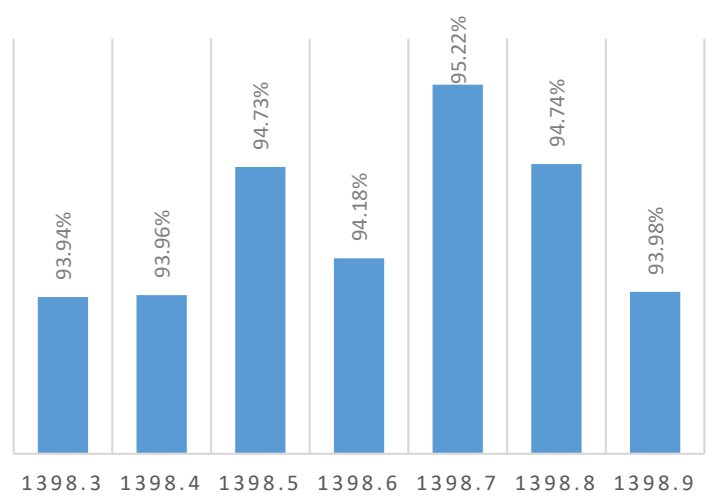

Figure 10. Successful transactions in 7 successive months. The solar calendar is customary in Iran. In this study, the data belong 7 successive months of the solar year 1398 regarding to Iranian calendar. In AD Calendar, 01/03/1398 is 2018/05/22.

Table 2 illustrates the TOPSIS assessments. The social column reports the preferences as average scores of the interviewed end users on a five-point scale. The other columns of the table (environmental economic influence, hardware and software availability and the cost) were scored according to the interviews with the experts of the PSP company: the scores are the averages of the experts' answers.

Table 2. TOPSIS calculation and ranking results.

\begin{tabular}{|c|c|c|c|c|c|c|c|}
\hline & & & $\operatorname{Max}$ & $\operatorname{Max}$ & $\operatorname{Max}$ & $\operatorname{Max}$ & Min \\
\hline & & Weight & 0.25 & 0.25 & 0.2 & 0.2 & 0.1 \\
\hline & & & \multicolumn{2}{|c|}{ Sustainability Pillars } & \multicolumn{3}{|c|}{ Company } \\
\hline & Alternatives & Sub Alternatives & Social & Env. And Econ. & Hardwar & Software & Cost \\
\hline A1 & Sms & Sms & 0.52 & 10 & 9 & 7 & 8 \\
\hline A2 & & Sms \& Print * & 0.53 & 9 & 8 & 7 & 9 \\
\hline A3 & Email & Email & 0.46 & 10 & 8 & 6 & 2 \\
\hline A4 & & Email \& Print* & 0.61 & 9 & 7 & 4 & 5 \\
\hline A5 & Application & Application & 0.52 & 10 & 10 & 7 & 4 \\
\hline A6 & & Application \& Print * & 0.54 & 9 & 9 & 6 & 5 \\
\hline \multirow{6}{*}{\multicolumn{2}{|c|}{ Normalized $^{1}$}} & A1 & 0.399174 & 0.429141 & 0.429547 & 0.45663 & 0.545595 \\
\hline & & A2 & 0.406851 & 0.386227 & 0.381819 & 0.45663 & 0.613795 \\
\hline & & A3 & 0.353116 & 0.429141 & 0.381819 & 0.391397 & 0.136399 \\
\hline & & A4 & 0.468262 & 0.386227 & 0.334092 & 0.260931 & 0.340997 \\
\hline & & A5 & 0.399174 & 0.429141 & 0.477274 & 0.45663 & 0.272798 \\
\hline & & A6 & 0.414527 & 0.386227 & 0.429547 & 0.391397 & 0.340997 \\
\hline \multirow{3}{*}{\multicolumn{3}{|c|}{$\begin{array}{l}\text { Positive Ideal Solution }{ }^{2} \\
\text { Negative Ideal Solution }^{3}\end{array}$}} & 0.117065 & 0.107285 & 0.095455 & 0.091326 & 0.01364 \\
\hline & & & 0.088279 & 0.096557 & 0.066818 & 0.052186 & 0.061379 \\
\hline & & & $\mathrm{S}+{ }^{4}$ & S- 5 & $C^{6}$ & & \\
\hline & & A1 & 0.04543 & 0.046804 & 0.507448 & & \\
\hline & & A2 & 0.054721 & 0.042468 & 0.436962 & & \\
\hline & & A3 & 0.036924 & 0.056268 & 0.603791 & & \\
\hline & & A4 & 0.053718 & 0.039659 & 0.424719 & & \\
\hline & & A5 & 0.022008 & 0.061339 & 0.735943 & & \\
\hline & & A6 & 0.031233 & 0.045002 & 0.590308 & & \\
\hline
\end{tabular}

${ }^{1} \overline{\text { Normalized matrix constructed regarding Formula (1) in Section } 2 \text { and then the weighted matrix constructed }}$ regarding Formula (2) but not presented in this table for more simplicity. ${ }^{2}$ Positive Ideal solution calculated regarding Formula (3) in Section 2. ${ }^{3}$ Negative Ideal solution calculated regarding Formula (4) in Section 2. ${ }^{4}$ Positive separation measure calculated regarding Formula (5) in Section $2 .{ }^{5}$ Positive separation measure calculated Formula (6) in Section 2. ${ }^{6}$ Relative closeness to the ideal solution calculated regarding Formula (7) in Section 2. ${ }^{*}$ If the transaction is successful, the system will send an eReceipt, otherwise the POS terminal will print a paper receipt for unsuccessful transaction. 


\section{Discussion}

\subsection{Responsible Consumption}

The habit of using the printed receipts is presently very common among sellers and end customers, who usually produce and take them. Such cultural aspect is key and should be changed. For instance, the owners of the POS terminals could inspect their reports online and save a digital copy instead of printing them. As results from the interviews with the SEM experts, using thermal printers for long reports results in wear of the mechanical parts, which require maintenance before schedule and maybe emergency maintenance service and, consequently, extra transportation. On the other hand, if the transaction is successful, both seller and buyer can refute the printed receipt. In fact, the end users often check the receipt once and threw it away immediately. Moreover, since the SMS reporting of the transactions is cheap in Iran-yet more expensive than email with Iran's national internet-all of the electronic payment users can be encouraged to use the SMS reporting service for their bank account; indeed, they can receive an immediate SMS from the bank for any withdrawal from the account. This means that, the habit of printing the receipt can be considered as a "false using culture," which could be changed by providing the users with accurate information.

According to the survey results, the majority of the respondents are aware of the toxicity of thermal papers, while a $34 \%$ are not aware of the environmental impact caused by the paper receipts. The histogram in Figure 7 shows how much the respondents are concerned with environmental issues, while the histogram in Figure 8 shows the number of respondents who habitually take the receipt after electronic payments in general. In addition, $54 \%$ of the respondents declare that they suggest to others to take the paper receipt. This confirms that even if the majority of subjects are aware of the environmental and safety issues, they have a strong tendency to use the traditional form of this complementary service. In sum, the respondents' environmental awareness and practices are not aligned.

Figure 9 shows the level of preference, on a 1-5 score, for using the paper receipt in a micro-zone in Tehran, in whole Tehran and in another city. Comparing the histograms B and C unveils that the social preference is very similar in different cities; on the contrary, the answers of the micro-zone appear to be rather different. In the specific, the chosen micro-zone is a commercial area with many shops and malls. It seems that in a commercial zone, users prefer to take the paper receipt after their transactions. This might be related to the characteristics of the commercial transaction which is strongly regulated by traditional habits. To sum up, in order to decrease the use of thermal paper receipts, efforts for cultural change and public awareness are the first step.

All the interviewed experts agree on the influential role played by the regulations related to online payment in Iran. According to the instructions of the standards SHP_STD_EFTPOSRECEIPT, providing a receipt is a necessary complementary service for PSP companies. Nevertheless, this receipt could be sent by email. The paper receipt is not a requirement but just a traditional way to provide this service, which established a habit and culture that could be changed. The dematerialization of the receipt, on the other hand, is technically possible by adding a new function script in the main software of the PSP company.

According to this regulation, the POS terminal must offer the opportunity to print the receipt, but the service provider can add another option besides printing. Therefore, even if the PSP company adopts greener alternatives, the "print" option must always be available: the selection depends on the client's decision. Furthermore, if the POS terminal cannot give the paper receipt, whenever the user selects the print alternative, the transaction fails. This legal necessity calls for a culture of responsible consumption. Indeed, the whole transition to a sustainable supply chain will strongly depend on the end users' requirements and preferences. It is the end user who chooses to print the receipt or accept a green alternative. In this case, a change of habit could result from a more widespread communication of the issues connected to the hazardous material on the thermal papers and the difficulties and social costs associated with recycling this paper. 
A revision of the regulation is also possible. In fact, every year representatives of the payment service sector and the authorities gather to review the obligations and rules, and survey the operations and functions of PSPs. Then, a stronger commitment to provide a greener service could be promoted within the updated regulation. On 15 September 2016, the Iranian government enacted the adoption of the agenda 2030 in all the cases where its goals are not contrary to the law. Moreover, on 10 May 2017 the Iranian foreign minister declared," We have no obligation to follow the agenda in cases that not comply with internal laws and customs". This means that the government will support the efforts to solve environmental issues. Since the elimination of hazardous material is associated with environmental issues, the Iranian government will also promote and support the requirements for the transition to a more sustainable supply chain in the payment service.

\subsection{Unnecessary Trips}

Thermal printers in POS terminals are the source of a considerable number of trips for maintenance. Classical POS terminals have more hardware problems and high-tech sets have more software problems. The majority of the POS terminals in Iran are classical models. Therefore, the best way to decrease the maintenance operations of the POS is through the reduction of the causes of hardware wear and roll replacement, which confirm the above-mentioned conclusion. In addition, in order to decrease the transportation waste, an optimization of the route travelled for maintenance by the technicians could be useful. In the selected zone, many of the inspection locations are closer than 50 meters together (see Figure 4). Since petrol is very cheap in Iran, there is an unintentional inclination to use internal combustion engine vehicles even for short distances, which is an important source of $\mathrm{CO}_{2}$ emission and traffic in big cities. These facts call for another cultural change to march a close distance on foot. To conclude, two kinds of improvement are required to decrease the transportation waste: first, the best route to reach all of the inspection points, and, second, the transportation means, from vehicle to foot.

\subsection{Disposal}

A robust plan for collecting the thermal paper receipts is still lacking. By all accounts, using thermal papers is not an eco-friendly way of reporting and monitoring the payments and transactions. The existing consumption of printed receipts is the source of a huge amount of thermal paper containing hazardous material. This paper waste is collected together with other solid waste and is frequently wrongly mixed with normal recyclable paper, thus contaminating the final product of the recycling activity. As previously remarked, at the end of the service supply chain there are two types of subjects, shop owners and end customers, who use the payment service and take the receipt. As for the end customers, only $17 \%$ of the respondents declared to separate the thermal paper as hazardous material, $36 \%$ of the respondents separate the paper from other kind of trash but they mix the receipts with other papers. On the other hand, there was only one of the interviewed shop owners who regularly collects the thermal receipts in a separated bin when the customer does not need to keep it anymore. To conclude, a robust plan for collecting the thermal paper waste especially in selling points and shops is necessary.

\subsection{The Best Alternative to Paper Receipt}

The TOPSIS evaluation shows that, according to the survey results, the most appropriate alternative to the thermal paper receipt in the service supply chain of SEP Co. is the notification sent by an application (app notification). This will be a great transition toward sustainability in the service sector in Iran. Nevertheless, as remarked by an interviewed Android POS Developer of the company, some cyber-security issues will arise in case of setting up the app notification instead of the thermal paper receipt. Moreover, several end users do not use the smart phones yet, while many smart phone owners will need tutoring to be able to use the app notification.

After the internet shutdown in Iran in November 2019, many internet users distrust internet-based services. However, the proposed service can be based on the national internet, which seems to be 
considered more reliable after that event. Still, the cyber security of the national internet will be an issue to be settled. To sum up, implementing the app notification needs more studies on cyber security, training programs for the end users and keeping the option of printing the receipt for the group of customers who do not use smartphones.

\subsection{Managerial Implications}

The interviewed experts agree that the adoption of alternative way of reporting in the service supply chain might affect the managerial processes of the company. It has been remarked that the investigated service is complementary; therefore, a possible dependence on external providers of IT services is possibly less problematic than the case of the core service. Nevertheless, the risk of lock-in cannot be neglected: partnership administration thus becomes a core managerial activity. Particularly in the supply chain planning phase, risk management becomes a necessary administrative measure to ensure that the service is resilient and sustainable. Furthermore, as previously observed, the identified alternatives require a close collaboration with the national internet service. This cooperation might reduce the power of the company's management on strategic decisions concerning technology selection and updating, thus diminishing the company's agility.

The experts concur that the introduction of the proposed solutions will have organizational benefits too, as it will simplify some resource-consuming processes (e.g., material flow management), which, in the specific case, are presently associated only to complementary services. Moreover, the transition to the eReceipt will reduce the maintenance of the POS terminals, and the associated direct costs, but also the administration cost for managing and scheduling the maintenance service and the operators. These outcomes will eventually free up management resources that can be assigned to the core services. In addition, a partnership with the key external service suppliers could provide a competitive advantage by using IT technology to design new value-added services or open up new markets.

\subsection{Limitations of the Study}

The main limitations of the present study concern the structure of the evaluation model and the general validity of the results. The MCDM model employs a small number of criteria related to sustainability. This allowed to reduce the time required for the interviews and their complexity, which was compatible with the available resources for the survey. However, in order to carry out a more detailed evaluation, a wider set of attributes of the concept "sustainability" should be used. The attribution of weights to the criteria, which in the present study were validated by the interviewed experts, could be more accurate by means of assessment procedures like the "swing weights" or pairwise comparisons. Still, such procedures require a more demanding interaction between interviewer and respondent. As far as the results are concerned, it must be remarked that they clearly depend on the surveyed samples. In particular, the identified alternatives to the printed receipt were validated by the SEP experts and they are probably applicable to other Iranian PSPs. Nevertheless, their acceptability in other contexts should be confirmed as it depends on the technology that is economically available and the legal requirements in force.

\section{Conclusions}

The service that is investigated in this study is made up of digital core services and complementary services that can be based on soft or hard activities. The end users value the opportunity to retrieve a receipt after a payment transaction and this is often regulated by the law. Traditionally, the receipt is printed on thermal paper, which is the source of waste and environmental costs. Therefore, this study addressed the first research question, i.e., what feasible substitutions of paper receipt can be implemented, by means of interviews with the company experts. Three main alternative ways and nine sub-alternatives were identified. The second question was addressed by ranking the alternatives according to a set of criteria proposed in agreement with the company experts. In summary, a reduction 
of the waste produced in the traditional service offered by the investigated PSP in Iran, is possible by offering two options to the users:

1. using the app notification as a rule;

2. printing the receipt only in particular cases-as previously noted, the legislation on electronic payment sets out this requirement.

The transition to the green service needs some changes in the core managerial activity like partnership administration and the elaboration of a risk management plan. On the other hand, the new configuration of the service could provide some organizational benefits, such as a leaner service supply chain and reduced administration costs. However, this approach has some limits that should be considered. Since the first option needs a cooperation with third parties, like Telecommunication Company of Iran, and providing some private data to the external companies, cyber security and customer privacy should be considered in the process of sending the eReceipt. In order to make the second option viable, it is necessary to raise the public awareness on the use and disposal of hazardous materials, and reinforce a responsible consumption behavior of the users of the payment service. On the other hand, the second option strongly depends on legal requirements and users' habit. In fact, the results of this study show that the public is well aware of the environmental and safety issues in general, but their declared preference for the traditional printed receipt markedly contrast with that. The complete substitution of the paper receipt with eReceipt will be possible only if public support for sustainable consumption is strong enough to influence the regulatory bodies and transform actual practices.

Supplementary Materials: 1. The Standard templates and conducted questionnaire available online at following addresses: a. https://www.surveymonkey.com, (Survey Monkey Templates: survey on environmental issues). b. http://survey.askform.cn. c. http://www.marketest.co.uk/market-research-questionnaire/548/ consumer_payment_methods. d. https://www.surveymonkey.com/r/LQCX7Q8, (Cashless System Questionnaire). e. https://www.surveymonkey.co.uk/r/RLHPWT5, (ePayment systems). 2. The survey results available online at: a. Pilot survey results: https://rive.google.com/file/d/1zQkmDvqaojj5xDE5Hb3OK1GKCtszyv43/ view? usp=sharing. b. Main survey results includes 600 interviews: https://drive.google.com/file/d/ 1VpMCQXmVNRiE71NYPgEHBMvalbYUt5WR/view?usp=sharing. c. TOPSIS analysis in Microsoft Excel: https://drive.google.com/file/d/1mDEuC73fJ19dVcLVL_0BDK1X20iVP7gJ/view?usp=sharing.

Future Works: The next study could focus on the cultural aspect of using non-eco-friendly material like thermal papers and possible ways to collect these receipts from both selling points and costumers. As mentioned in the conclusion section, there is no plan to collect the receipts in selling points and shops in any country. In order to give a more specific technical grounding to the evaluation of alternative solutions, the future study should consider the life-cycle of the complementary service in the different forms. Another future research could be the optimization of the routes between the selling points to save time and decrease the number of trips.

Author Contributions: For this research article three authors cooperated. A.A.A. contributed in defining the research questions, the scope and main objectives; he set clear measurement priorities, conducted the literature review, data analysis, data visualization, interpret Results, and wrote the draft of the paper. E.P. defined the research questions, the scope and main objectives, supervised the literature review, data analysis, data visualization, the interpretation of the results, and refined the final draft of the paper. N.R. contributed in the definition of the research questions, scope and main objectives; she set the measurement priorities, performed data collection, interviews and provided material such as the pictures and supported data interpretation. All authors have read and agreed to the published version of the manuscript.

Funding: This research received no external funding.

Acknowledgments: We acknowledge Mehdi Ahmadi director of the Department of Research \& Planning for his kind support and giving permission to perform this academic study.

Conflicts of Interest: The authors declare no conflict of interest.

\title{
Appendix A. Pilot Survey Analysis Code in Python
}

\author{
import pandas as pa \\ import numpy as np \\ import matplotlib \\ matplotlib.use('TkAgg')
}


import matplotlib.pyplot as plt

Missing_values = ["nan", " ", " ", "NaN", "-", "n/a"]

Pi_Qu = pa.read_csv(" $\backslash \backslash \ldots$ Adress $\ldots . \backslash \backslash$ PilotQues.csv", na_values = Missing_values $)$

Is_null $=$ Pi_Qu.isnull $($ )

Null_sum $=$ Pi_Qu.isnull().sum()

$\mathrm{Pi} \_\mathrm{Qu}=\mathrm{Pi} \_\mathrm{Qu}$. replace $\left(\mathrm{r}^{\prime \wedge} \mid \mathrm{s}^{*} \$^{\prime}, \mathrm{np}\right.$. nan, regex=True)

Pi_Qu["WHICH OPTION IS MORE SUITABLE FOR YOU"].replace(to_replace = np.nan, value $=$ "No Idea", inplace $=$ True, regex $=$ True)

$\mathrm{Pi} \_\mathrm{Qu}[$ "AWARENESS"].replace(to_replace $=$ np.nan, value $=" N O$ ", inplace $=$ True, regex=True)

Null_sum_nanFilled $=$ Pi_Qu.isnull().sum()

Pi_Qu.drop("NO.", axis=1, inplace=True)

Headers = Pi_Qu.columns

print(Pi_Qu.dtypes)

print(Pi_Qu.describe())

Pi_Qu_AgeSort = Pi_Qu.sort_values("AGE", ascending=True)

SEX = Pi_Qu['SEX'].value_counts()

$\operatorname{print}(\mathrm{SEX})$

Education $=$ Pi_Qu['EDU'].value_counts()

print(Education)

Outlier_Detection = Pi_Qu.loc[(Pi_Qu["NESSECITY OF TAKE A RECIEPT "] == "NOT AT AL") \& (Pi_Qu["SUGGEST TO OTHERS"] == "YES")]

Pi_Qu1 = Pi_Qu[:19]

Pi_Qu2 = Pi_Qu[20:]

Pi_Qu2 = Pi_Qu2.reset_index()

Pi_Qu2.drop("index", axis=1, inplace=True)

Catagorical_Comparison $1=$ Pi_Qu1['RECIEPT AFTER TRANSACTION.GENERAL'].value_counts ()

Catagorical_Comparison2 = Pi_Qu2['RECIEPT AFTER TRANSACTION.GENERAL'].value_counts() reorder_list $=$ ['Always', 'Most of the time', 'About half of the time ', 'Once in a while ', 'NEVER']

Catagorical_Comparison1r $=$ Catagorical_Comparison1.reindex(reorder_list)

Catagorical_Comparison2r $=$ Catagorical_Comparison2.reindex(reorder_list)

plt.style.use('default')

$\mathrm{x}=$ np.arange $(5)$

plt.bar $\left(x+0.00\right.$, Catagorical_Comparison1r, color $=$ ' $^{\prime}$, width $=0.25$, label='First half $\left.{ }^{\prime}\right)$

plt.bar $\left(x+0.25\right.$, Catagorical_Comparison2r, color $={ }^{\prime} g$ ', width $=0.25$, label='Second half')

plt.title('Reliability Test')

plt.xlabel('Likert Scale', fontweight='bold')

plt.xticks([x + 0.125 for $x$ in range(5)], ['Always', 'Most of the time', 'About half of the time ', 'Once

in a while ', 'NEVER'], rotation $=45$, fontsize $=$ 'small')

plt.legend()

plt.grid()

plt.autoscale()

plt.show() 


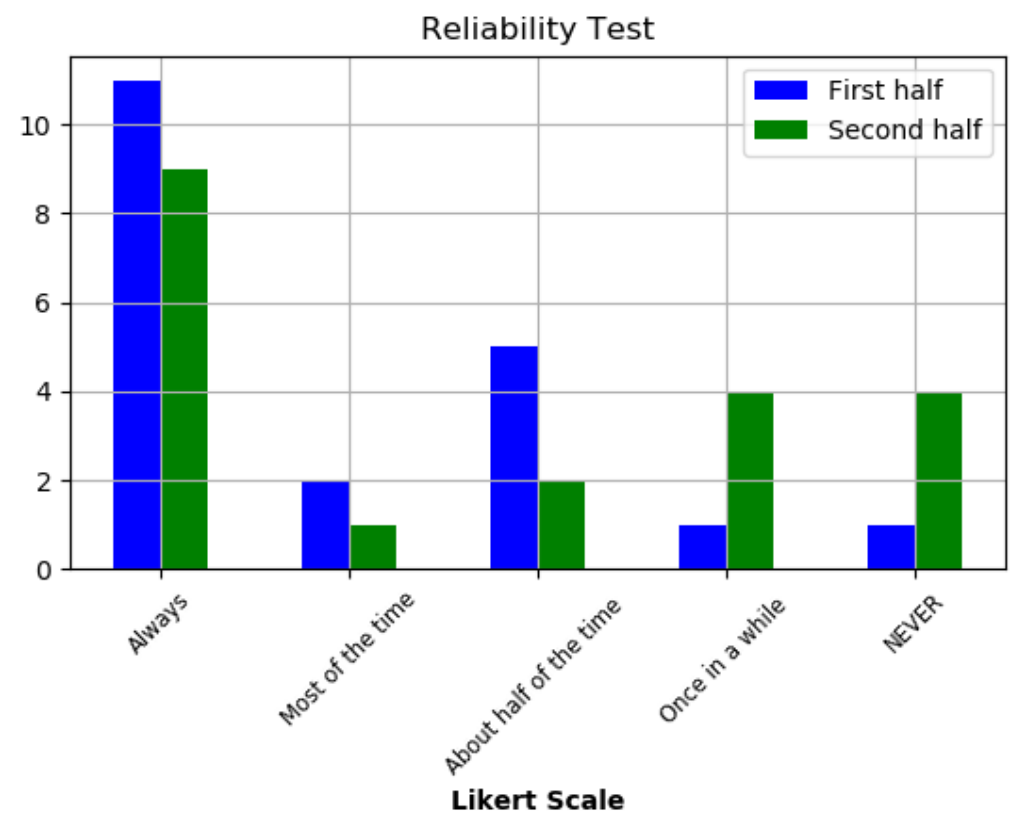

Figure A1. Comparison of the results of 2 pilot survey on "feeling the necessity of take a paper receipt".

\section{References}

1. Ibelbena.ir. Available online: http://www.ibena.ir/news/97230/ (accessed on 22 February 2020).

2. Yagooby, M. Khabaronline.it. Available online: https://www.khabaronline.ir/news/390750/ (accessed on 22 February 2020).

3. Taghikhah, F.; Voinov, A.; Shukla, N. Extending the supply chain to address sustainability. J. Clean. Prod. 2019, 229, 652-666. [CrossRef]

4. Pagell, M.; Shevchenko, A. Why Research in Sustainable Supply Chain Management Should Have no Future. J. Supply Chain Manag. 2014, 50, 44-55. [CrossRef]

5. Gruner, R.L.; Power, D. Mimicking natural ecosystems to develop sustainable supply chains: A theory of socio-ecological intergradation. J. Clean. Prod. 2017, 149, 251-264. [CrossRef]

6. Papetti, A.; Marconi, M.; Rossi, M.; Germani, M. Web-based platform for eco-sustainable supply chain management. Sustain. Prod. Consum. 2019, 17, 215-228. [CrossRef]

7. Hussain, M.; Ajmal, M.M.; Gunasekaran, A.; Khan, M. Exploration of social sustainability in healthcare supply chain. J. Clean. Prod. 2018, 203, 977-989. [CrossRef]

8. Liu, W.; Bai, E.; Liu, L.; Wei, W. A Framework of Sustainable Service Supply Chain Management: A Literature Review and Research Agenda. Sustainability 2017, 9, 421. [CrossRef]

9. O'Mahony, D.; Peirce, M.A.; Tewari, H. Electronic Payment Systems; The Artech House Computer Science Library; Artech House: Boston, MA, USA, 1997; ISBN 978-0-89006-925-7.

10. Vinci, G.; Musarra, M. Digital services for new model of sustainable mobility. In Digitally Supported Innovation; Caporarello, L., Cesaroni, F., Giesecke, R., Missikoff, M., Eds.; Springer: Cham, Switzerland, 2016; pp. 235-246.

11. Johansson, N. Smart mobility Through Multi-Level Innovation. In Proceedings of the 20th ITS World Congress, Tokyo, Japan, 14-18 October 2013; ITS Japan: Tokyo, Japan.

12. Valentina, V.; Opromolla, A.; Parente, G.A.; Medaglia, C.M. Towards a Multi-modal Transportation Scenario: An Analysis About Elderly Needs. In International Conference on Human-Computer Interaction; Springer Nature: Cham, Switzerland, 2019; pp. 118-129.

13. Solarte-Vasquez; Claudia, M.; Järv, N.; Nyman-Metcalf, K. Usability factors in transactional design and smart contracting. In The Future of Law and eTechnologies; Kerikmäe, T., Rull, A., Eds.; Springer Nature: Cham, Switzerland, 2016; pp. 149-176.

14. Sarin, G. Developing smart cities using Internet of Things: An empirical study. In Proceedings of the 3rd International Conference on Computing for Sustainable Global Development (INDIACom), New Delhi, India, 16-18 March 2016; IEEE: New Delhi, India; pp. 315-320. 
15. Schreieck, M.; Wiesche, M.; Krcmar, H. Modularization of Digital Services for Urban Transportation. In Proceedings of the AMCIS 2016, 22nd Americas Conference on Information Systems, San Diego, USA, 11-14 August 2016.

16. Chris, P.; Schien, D.; Shabajee, P. Evaluating Sustainable Interaction Design of Digital Services: The Case of YouTube. In Proceedings of the 2019 CHI Conference on Human Factors in Computing Systems, Glasgow, UK, 4-9 May 2019; pp. 1-12.

17. Koukopoulos, Z.; Koukopoulos, D.; Jung, J.J. Sustainability Services for Public Libraries within a Smart City Environment. In Proceedings of the 9th International Conference on Web Intelligence, Mining and Semantics, Seoul, Korea, 26-28 June 2019; Association for Computing Machinery: Seoul, Korea, 2019; pp. 1-12.

18. Kölmel, B.; Bulander, R.; Dittmann, U.; Schätter, A.; Kühn, A. Sustainability and competitiveness through digital product-service-systems. In Proceedings of the eChallenges e-2015 Conference, Vilnius, Lithuania, 25-27 November 2015; pp. 1-9.

19. Agbozo, E. Developing a digital government framework for Sub-Saharan Africa. In Proceedings of the 17th European Conference on Digital Government, ECDG 2017, Lisbon, Portugal, 12-13 June 2017; Academic Conferences and Publishing International Limited: Reading, UK, 2017; pp. 294-305.

20. Sánchez-Montesinos, F.; Basáez, M.O.; Aranda, D.A.; Bustinza, O.F. Creating isolating mechanisms through digital servitization: The case of Covirán. Strateg. Chang. 2018, 27, 121-128. [CrossRef]

21. Marić, J.; Opazo-Basáez, M. Green Servitization for Flexible and Sustainable Supply Chain Operations: A Review of Reverse Logistics Services in Manufacturing. Glob. J. Flex. Syst. Manag. 2019, 20, 65-80. [CrossRef]

22. Vendrell-Herrero, F.; Bustinza, O.F.; Opazo-Basaez, M. Information technologies and product-service innovation: The moderating role of service R\&D team structure. J. Bus. Res. 2020. [CrossRef]

23. Bustinza, O.F.; Vendrell-Herrero, F.; Gomes, E.; Lafuente, E.; Opazo-Basaez, M.; Rabetino, R.; Vaillant, Y. Product-service innovation and performance. Int. J. Bus. Environ. 2018, 10, 95-111. [CrossRef]

24. Visnjic-Kastalli, I.; Van Looy, B. Servitization: Disentangling the impact of service business model innovation on manufacturing firm performance. J. Oper. Manag. 2013, 31, 169-180. [CrossRef]

25. Rochester, J.R. Bisphenol A and human health: A review of the literature. Reprod. Toxicol. 2013, 42, $132-155$. [CrossRef]

26. Calafat, A.M.; Zsuzsanna, K.; Reidy, J.A.; Samuel, C.P.; John, E.; Larry, N.L. Urinary Concentrations of Bisphenol A and 4-Nonylphenol in a Human Reference Population. Environ. Health Perspec. 2005, 113, 391-395. [CrossRef] [PubMed]

27. Vandenberg, L.N. Exposure to bisphenol A in Canada: Invoking the precautionary principle. CMAJ 2011, 183, 1265-1270. [CrossRef] [PubMed]

28. Vandenberg, L.N.; Ehrlich, S.; Belcher, S.M.; Ben-Jonathan, N.; Dolinoy, D.C.; Hugo, E.R.; Hunt, P.A.; Newbold, R.R.; Rubin, B.S.; Saili, K.S.; et al. Low dose effects of bisphenol A. Endocr. Disruptors 2013, 1, e26490. [CrossRef]

29. Heindel, J.J.; Balbus, J.; Birnbaum, L.; Brune-Drisse, M.N.; Grandjean, P.; Gray, K.; Landrigan, P.J.; Sly, P.D.; Suk, W.; Cory Slechta, D.; et al. Developmental Origins of Health and Disease: Integrating Environmental Influences. Endocrinology 2015, 156, 3416-3421. [CrossRef]

30. Balezentis, T.; Chen, X.; Galnaityte, A.; Namiotko, V. Optimizing crop mix with respect to economic and environmental constraints: An integrated MCDM approach. Sci. Total Environ. 2020, 705, 135896. [CrossRef]

31. Martinez-Cordero, F.J.; Leung, P.S. Multicriteria decision making (MCDM) model for regional sustainable shrimp farming development in northwest Mexico. Aquac. Econ. Manag. 2004, 8, 179-192. [CrossRef]

32. Fargnoli, M.; Costantino, F.; Di Gravio, G.; Tronci, M. Product service-systems implementation: A customized framework to enhance sustainability and customer satisfaction. J. Clean. Prod. 2018, 188, 387-401. [CrossRef]

33. Zhao, Q.; Tsai, P.-H.; Wang, J.-L. Improving Financial Service Innovation Strategies for Enhancing China's Banking Industry Competitive Advantage during the Fintech Revolution: A Hybrid MCDM Model. Sustainability 2019, 11, 1419. [CrossRef]

34. Raut, R.; Cheikhrouhou, N.; Kharat, M. Sustainability in the Banking Industry: A Strategic Multi-Criterion Analysis. Bus. Strategy Environ. 2017, 26, 550-568. [CrossRef]

35. Liu, Y.; Yang, Y.; Liu, Y.; Tzeng, G.-H. Improving Sustainable Mobile Health Care Promotion: A Novel Hybrid MCDM Method. Sustainability 2019, 11, 752. [CrossRef]

36. Moslem, S.; Ghorbanzadeh, O.; Blaschke, T.; Duleba, S. Analysing Stakeholder Consensus for a Sustainable Transport Development Decision by the Fuzzy AHP and Interval AHP. Sustainability 2019, 11, 3271. [CrossRef] 
37. Ozturkoglu, Y.; Sari, F.O.; Saygili, E. A new holistic conceptual framework for sustainability oriented hospitality innovation with triple bottom line perspective. J. Hosp. Tour. Res. 2019. [CrossRef]

38. Legard, r.; Keega, J.; Ward, K. In-depth Interviews. In Qualitative Research Practice: A Guide for Social Science Students and Researchers; SAGE Publishing: Thousand Oaks, CA, USA, 2003; pp. 139-168. ISBN 978-0-7619-7110-8.

39. Takata, S.; Kirnura, F.; van Houten, F.J.A.M.; Westkamper, E.; Shpitalni, M.; Ceglarek, D.; Lee, J. Maintenance: Changing Role in Life Cycle Management. Cirp Ann. 2004, 53, 643-655. [CrossRef]

40. Roy, R.; Stark, R.; Tracht, K.; Takata, S.; Mori, M. Continuous maintenance and the future - Foundations and technological challenges. Cirp Ann. 2016, 65, 667-688. [CrossRef]

41. Top 150 Merchant Acquirers Worldwide. In Card and Mobile Payment Industry News; The Nilson Report Issue: 2018. p. 11. Available online: https://nilsonreport.com (accessed on 20 February 2020).

42. Shaparak. Electronic Payment Network, Instruction and Regulations of Payment Receipt in Selling Points; Shaparak: Tehran, Iran, 2017.

43. Connelly, L.M. Pilot studies. Medsurg. Nurs. 2008, 17, 411-412.

44. Hill, R. What Sample Size Is “Enough" In Internetsurvey Research? Ipct-J. Electron. J. 21st Century 1998, 6, $1-12$.

45. Isaac, S.; Bell, M.E.; Michael, W.B. Handbook in Research and Evaluation; EdITS Publishers: San Diego, CA, USA, 1981; p. 234.

46. Treece, E.W.; Treece, J.W.J. Elements of research in nursing: Second Edition. Nursing2020 1977, 7, $12-13$. [CrossRef]

47. El Amine, M.; Pailhes, J.; Perry, N. Comparison of different Multiple-criteria decision analysis methods in the context of conceptual design: Application to the development of a solar collector structure. In Proceedings of the Joint Conference on Mechanical, Design Engineering \& Advanced Manufacturing, Toulouse, France, 18-20 June 2014; pp. 1-6.

48. Roszkowska, E. Multi-criteria Decision Making Models by Applying the Topsis Method to Crisp and Interval Data. Mult. Criteria Dec. Mak. 2011, 6, 200-230.

49. Dehghani Soufi, M.; Ghobadian, B.; Najafi, G.; Sabzimaleki, M.R.; Yusaf, T. TOPSIS Multi-Criteria Decision Modeling Approach for Biolubricant Selection for Two-Stroke Petrol Engines. Energies 2015, 8, 13960-13970. [CrossRef]

50. Wangchen Bhutia, P.; Phipon, R. Appication of AHP and TOPSIS method for supplier selection problem. IOSR J. Eng. 2012, 2, 43-50. [CrossRef]

(C) 2020 by the authors. Licensee MDPI, Basel, Switzerland. This article is an open access article distributed under the terms and conditions of the Creative Commons Attribution (CC BY) license (http://creativecommons.org/licenses/by/4.0/). 